\title{
A salient-pole PMSM position and speed estimation at standstill and low speed by a simplified HF injection method
}

\author{
S. Medjmadj ${ }^{1}$, D. Diallo² IEEE Senior Member, C. Delpha ${ }^{3}$ IEEE Member, G. Yao ${ }^{4}$ \\ ${ }^{1}$ Laboratoire d'Automatique de Setif (LAS), Univ. Bordj Bou Arreridj, Algeria. \\ s.medjmadj@univ-bba.dz \\ ${ }^{2}$ Group of Electrical Engineering Paris (GeePs), CNRS UMR 8507, CentraleSupélec, Univ. Paris Sud, UPMC, \\ France; demba.diallo@geeps.centralesupelec.fr \\ ${ }^{3}$ Laboratory of Signals and Systems (L2S), CNRS UMR 8506, CentraleSupélec, Univ. Paris Sud, France \\ claude.delpha@12s.centralesupelec.fr \\ ${ }^{4}$ Shanghai Maritime University, Shanghai, China, \\ gangyao@shmtu.edu.cn
}

\begin{abstract}
This paper addresses the estimation of a permanent magnet synchronous machine mechanical position and speed estimation at low speed and standstill. The method is based on the injection of an additive voltage at High Frequency (HF), which exploits the position dependency to the magnetic saliency. Unlike the usual HFI method, this estimator has a simple structure with only one filter. The simulation results prove the efficacy of the estimation under no load and with a load torque in the low speed region and at standstill. The mechanical position estimation errors are lower than $0.035 \mathrm{rad}$ $\left(2^{\circ}\right)$.
\end{abstract}

Index Terms - Permanent-Magnet Synchronous Machine (PMSM), Sensorless control, High Frequency Signal Injection, Low speed.

\section{INTRODUCTION}

Permanent Magnet Synchronous Machines (PMSM) have been receiving an increasing attention in several industrial sectors because of its simplicity of design, ability of operation at high speeds, high efficiency and high power/torque density.

The traditional approach to ensure high performance whatever the operation conditions is to install a mechanical sensor at the detriment of the robustness and the system cost. Herein, we address both existing problematic:

- Ensure stable and robust motor operation in the low speed area without a mechanical sensor;

- Reach comparable level of performance between operation with sensor and without sensor at low and zero speed.

Sensorless control is useful to reduce the cost of the application, or when there is no room for a mechanical sensor. For sensorless applications at high speed, accurate estimations can be obtained with techniques such as Kalman filters [1], the reference models (MRAS) [2] or adaptive observers [3]. However, these methods fail to deliver satisfactory performance at zero or very low speed.

In this case, thanks to the magnetic saliency, signal-injection methods [4] (voltage pulse or high frequency voltage) lead to more accurate estimations. For both methods, one should pay attention to the level of additional torque ripples when selecting the signal properties [5].

The main drawback of voltage pulse is that this method requires the perfect synchronization of the current measurements with the PWM to avoid the noise perturbations.

For the high frequency injection method, its main drawback is related to the rotor position processing from the measured currents. This operation requires three filters and two rotations. Hereafter we propose to evaluate a more straightforward method that should be as accurate in the low-speed range and at standstill.

The rest of the paper is organized as follows. Section II is devoted to the model of the PMSM. In Section III we explain the proposed position and speed estimations procedures of PMSM at low speed by HF voltage injection using only one low-pass filter. The simulation results are presented in Section IV. Finally a conclusion closes the paper.

\section{MODEL OF THE PMSM}

For a permanent magnet synchronous motor the stator voltages in the rotor reference frame can be described as follows:

$$
\left[\begin{array}{l}
V_{d} \\
V_{q}
\end{array}\right]=\left[\begin{array}{cc}
R_{s} & 0 \\
0 & R_{s}
\end{array}\right]\left[\begin{array}{l}
i_{d} \\
i_{q}
\end{array}\right]+\left[\begin{array}{cc}
\rho & -w_{r} \\
w_{r} & \rho
\end{array}\right]\left[\begin{array}{l}
\psi_{d} \\
\psi_{q}
\end{array}\right]
$$


Where $\rho$ is a differential operator. The magnetic flux is given by:

$$
\left[\begin{array}{l}
\psi_{d} \\
\psi_{q}
\end{array}\right]=\left[\begin{array}{cc}
L_{d} & 0 \\
0 & L_{q}
\end{array}\right]\left[\begin{array}{l}
i_{d} \\
i_{q}
\end{array}\right]+\left[\begin{array}{l}
\psi_{m} \\
0
\end{array}\right]
$$

Transforming (1) into the stationary reference frame $\left(w_{r}=0\right)$ results in the following stator voltage equations:

$\left[\begin{array}{c}V_{\alpha} \\ V_{\beta}\end{array}\right]=\left[\begin{array}{cc}R_{s} & 0 \\ 0 & R_{s}\end{array}\right]\left[\begin{array}{l}i_{\alpha} \\ i_{\beta}\end{array}\right]+\left[\begin{array}{cc}\rho & 0 \\ 0 & \rho\end{array}\right]\left[\begin{array}{l}\psi_{\alpha} \\ \psi_{\beta}\end{array}\right]$

The transformed stator flux linkages can be described as:

$$
\begin{aligned}
{\left[\begin{array}{l}
\psi_{\alpha} \\
\psi_{\beta}
\end{array}\right] } & =\left[\begin{array}{cc}
-\Delta L \sin \left(2 \theta_{r}\right) & L-\Delta L \cos \left(2 \theta_{r}\right) \\
L+\Delta L \cos \left(2 \theta_{r}\right) & -\Delta L \sin \left(2 \theta_{r}\right)
\end{array}\right]\left[\begin{array}{c}
i_{d} \\
i_{q}
\end{array}\right] \\
& +\psi_{m}\left[\begin{array}{l}
\cos \left(\theta_{r}\right) \\
\sin \left(\theta_{r}\right)
\end{array}\right]
\end{aligned}
$$

Where $L$ and $\Delta L$ are the average inductance (average stator transient inductance) and the amplitude of the spatial modulation of the inductance (differential stator transient inductance) [6], [7].

where $L=\frac{L_{d}+L_{q}}{2}$ and $\Delta L=\frac{L_{q}-L_{d}}{2}$.

\section{HF INJECTION FOR SENSORLESS CONTROL}

Several authors have studied the injection of a rotating high frequency (HF) voltage for saliency tracking $[8,9]$. The high frequency injection voltages with constant amplitude $V_{s i}$ and angular frequency $\omega_{i}$ are described as follows [10, 11]:

$\left[\begin{array}{l}V_{\alpha i} \\ V_{\beta i}\end{array}\right]=V_{s i}\left[\begin{array}{l}-\sin \left(\omega_{i} t\right) \\ \cos \left(\omega_{i} t\right)\end{array}\right]$

In [5], the authors have studied the voltage amplitude selection issue and its consequences on the performances of the position estimation.

For high frequency signals the stator resistance and the effects of the permanent magnet flux linkages can be neglected. A PMSM has a small saliency mainly due to stator saturation from the main magnets. The following HF currents are obtained [11]:

$$
\left[\begin{array}{c}
i_{\alpha i} \\
i_{\beta i}
\end{array}\right]=\left[\begin{array}{c}
I_{i 0} \cos \left(\omega_{i} t\right)+I_{i 1} \cos \left(2 \theta_{r}-\omega_{i} t\right) \\
I_{i 0} \sin \left(\omega_{i} t\right)+I_{i 1} \sin \left(2 \theta_{r}-\omega_{i} t\right)
\end{array}\right]
$$

With:

$$
I_{i 0}=\frac{V_{s i}\left(L_{q}+L_{d}\right)}{2 \omega_{i} L_{d} L_{q}} ; I_{i 1}=\frac{V_{s i}\left(L_{q}-L_{d}\right)}{2 \omega_{i} L_{d} L_{q}}
$$

Equation (6) reveals a negative-sequence signal proportional to the saliency $\left(L_{q}-L_{d}\right)$ that contains information on twice the rotor position $2 \hat{\theta}_{r}$ [11-13].

The rotor position estimate $\hat{\theta}_{r}$ can be retrieved from the high frequency currents derived from the measured currents as displayed in Figure 1

The processing is based on the use of three filters (a lowpass Filter (LPF) a high pass filter (HPF), a band pass-filter (BPF) and two rotations.

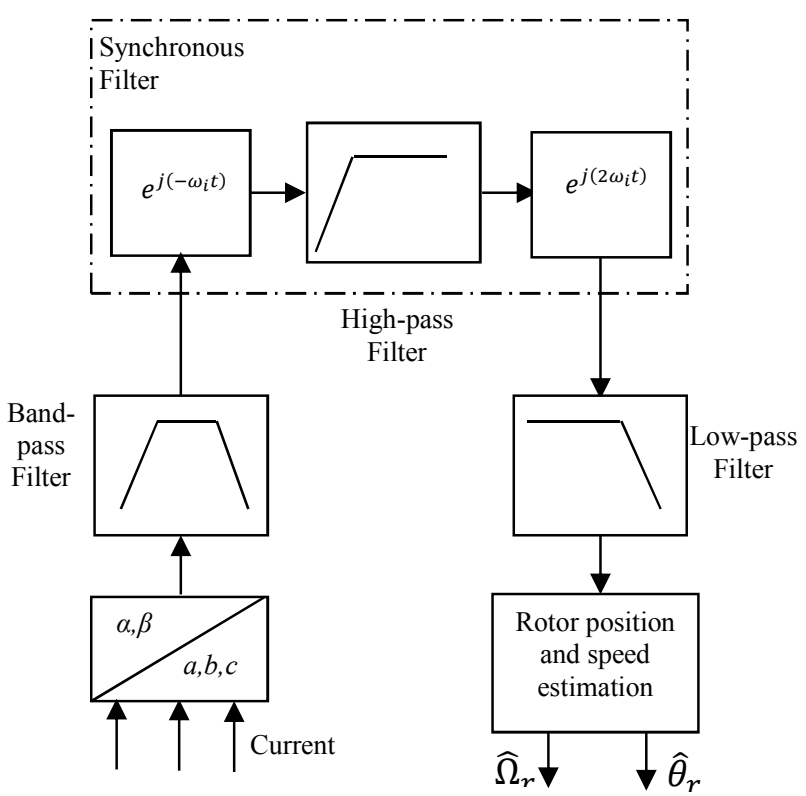

Fig.1. Synchronous filters for demodulation of HF currents.

In order to reduce the computational burden of the estimation, a simplified version is displayed in figure 2 . It consists of using only one fourth-order low-pass filter (LPF) and one rotation. The low-pass-filter is used to attenuate the low frequency excitation component.

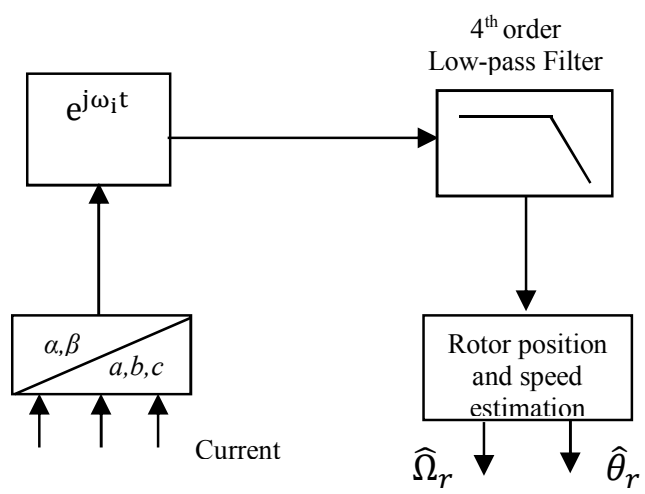

Fig.2. Simplified method for rotor position and speed estimations 


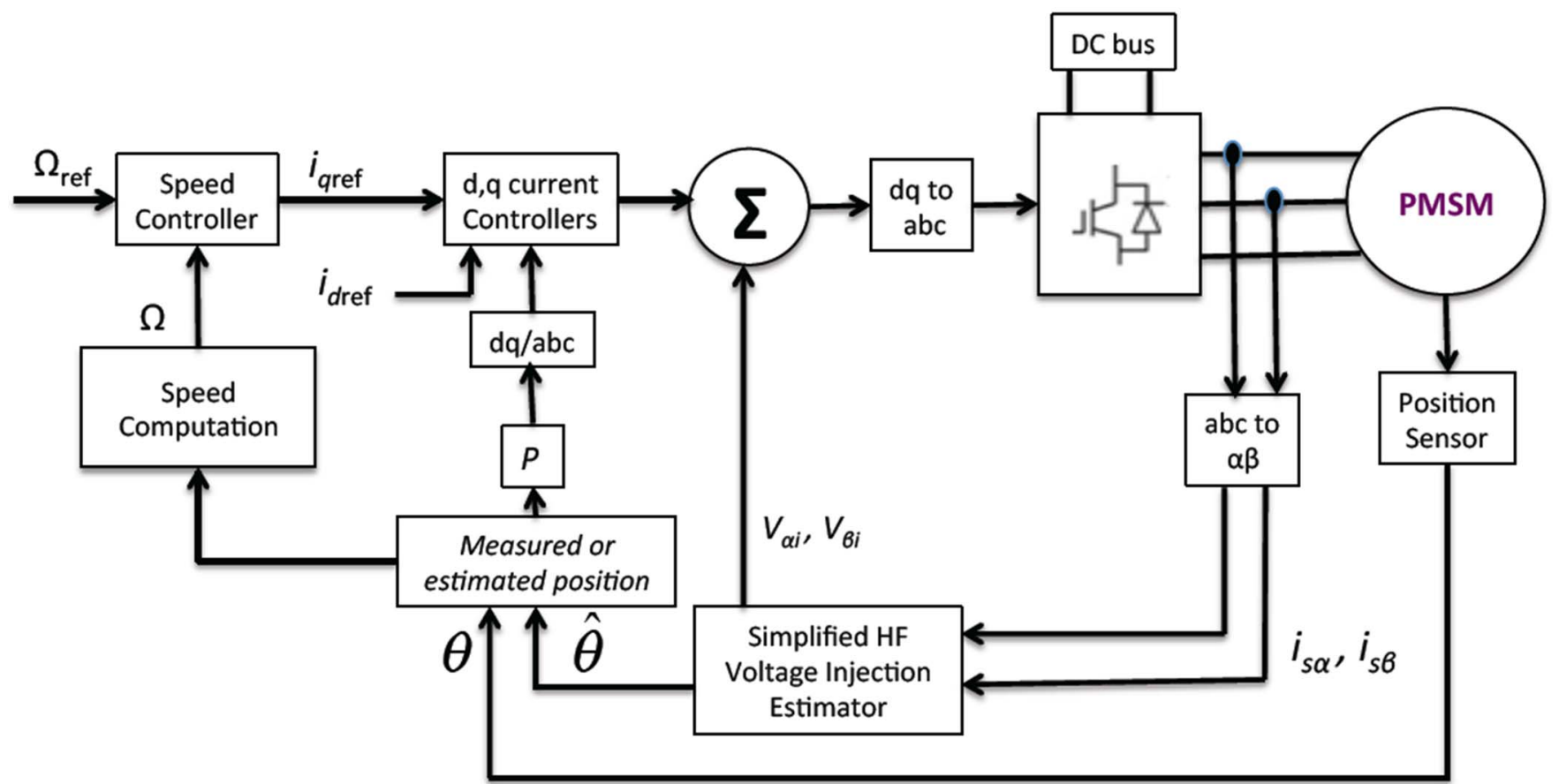

Fig.3. Speed control structure with the simplified HF voltage injection.

\section{SimULATION RESUlTS}

The simulations are performed with Matlab-Simulink ${ }^{\circledR}$. The parameters of the PMSM are listed in Table I. The operating point is set in the low speed region $(\Omega<$ $\left.10 \Omega_{\mathrm{n}} \%\right)$ at no load.

The general PMSM control system structure investigated in this work is shown in Fig. 3. The control system includes a salient-pole PMSM drive, an inverter, a pulse width modulation (PWM) module, two coordinate transformation modules, two controllers and the HFI estimator.

The machine is fed through a voltage source inverter, and a field oriented voltage vector control is used to drive the PMSM drive. The current control algorithm is carried out every $100 \mu \mathrm{s}$, and the speed control loop is carried out every $1 \mathrm{~ms}$. The inverter switching frequency is $20 \mathrm{kHz}$, and the DC bus voltage is set at $200 \mathrm{~V}$.

To evaluate the performances of the HFI method, the position sensor is used for the control and the estimated position is compared to the actual one.

In sensorless mode, the estimated position is used for the control (to compute the speed and the Park transformations).

Solid lines represent the actual mechanical speed and position, and dashed lines represent the estimations. The average speed and position estimation errors at steady state are almost zero. The simulation results under no load torque are presented in Fig.4 and Fig.5.

TABLE I: PMSM CHARACTERISTICS

\begin{tabular}{lll}
\hline \hline Symbol & Quantity & Value and Unit \\
& & \\
\hline$\Psi \mathrm{m}$ & Magnetic flux & $0.153 \mathrm{~Wb}$ \\
$\Omega \mathrm{n}$ & Nominal speed & $314 \mathrm{rad} / \mathrm{s}$ \\
$\mathrm{Tn}$ & Load torque & $3.2 \mathrm{Nm}$ \\
$\mathrm{Ld}$ & d axis inductance & $3.5 \mathrm{mH}$ \\
$\mathrm{Lq}$ & q axis inductance & $4.5 \mathrm{mH}$ \\
$\mathrm{Rs}$ & Stator resistance & $1.65 \Omega$ \\
$\mathrm{J}$ & Inertia & $6.410-3 \mathrm{~kg} / \mathrm{m}^{2}$ \\
$\mathrm{~F}$ & Viscous friction & $50910-3 \mathrm{Nm} / \mathrm{rad}$ \\
$\mathrm{p}$ & Pole pairs & 3 \\
$\mathrm{Vn}$ & Nominal voltage & $200 \mathrm{~V}$ \\
$\mathrm{In}$ & Nominal current & $6 \mathrm{~A}$ \\
\hline \hline
\end{tabular}

Fig. 4 shows the speed and position waveforms of the PMSM drive under no load. We can observe the good tracking capabilities with good dynamic performances. We can also notice the rapid convergence of the estimations.

The average speed and position estimation errors are almost zero. The oscillations are mainly due to the PWM of the inverter.

The average position estimation error is equal to $0.015 \mathrm{rad}$ $\left(0.85^{\circ}\right)$. During the transients, the maximal speed estimation error is equal to $0.02 \%$ and the maximal position error is equal to $0.032 \mathrm{rad}\left(1.8^{\circ}\right)$. 


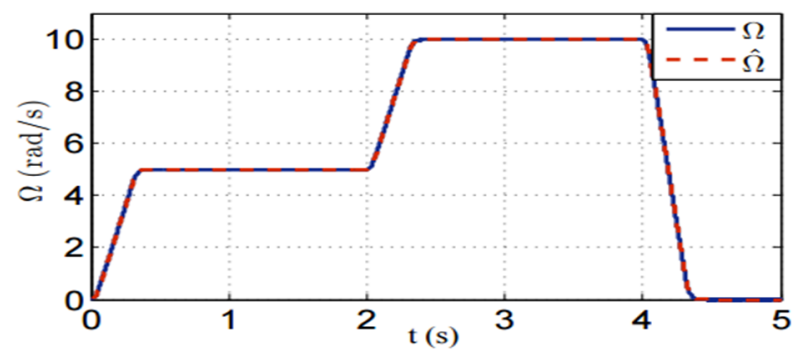

a. Actual and estimated speeds

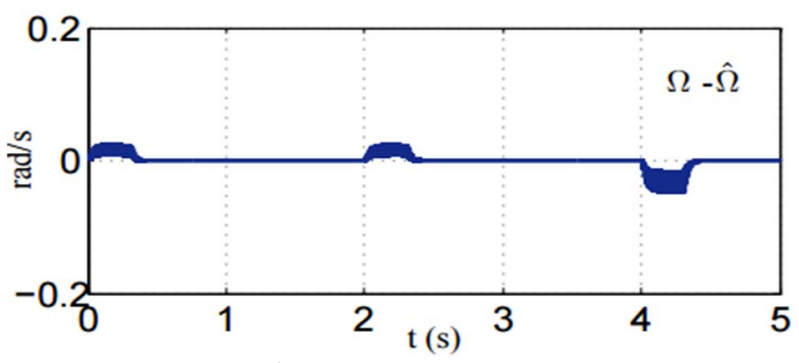

b. Rotor speed estimation error

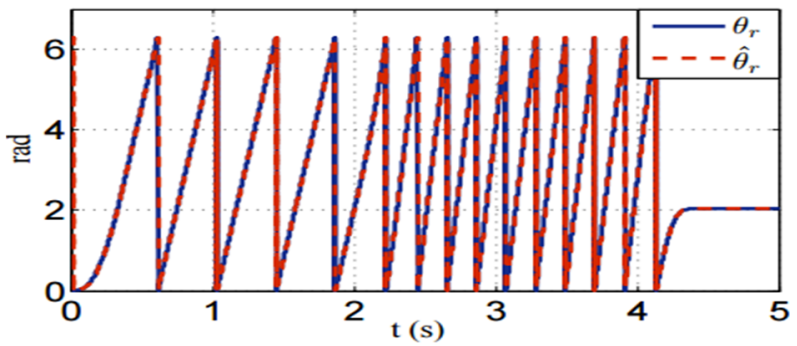

c. Actual and estimated rotor position

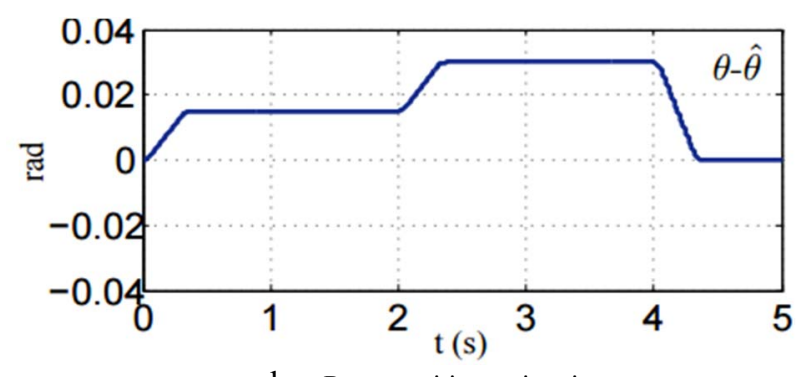

d. Rotor position estimation error

Fig.4. Speed and position waveforms under no load with the simplified HFI method.

Looking at figures 4 and 5, we can conclude that the simplified method exhibits comparable performances with the usual method. Despite a higher position estimation error (in fact lower than $0.03 \mathrm{rad}$ ), the speed estimation error is lower during the transients.

We can then adopt this method for sensorless operation and evaluate in the following.

In the following we present the simulation results with a load torque at standstill and low speed using the simplified HFI.
During this test, the speed of the motor varies in the low speed region between $\left(0 \% \Omega_{n} \leq \Omega \leq 10 \% \Omega_{n}\right)$, where $\Omega_{\mathrm{n}}$ is the nominal speed in $\mathrm{rad} / \mathrm{s}$.

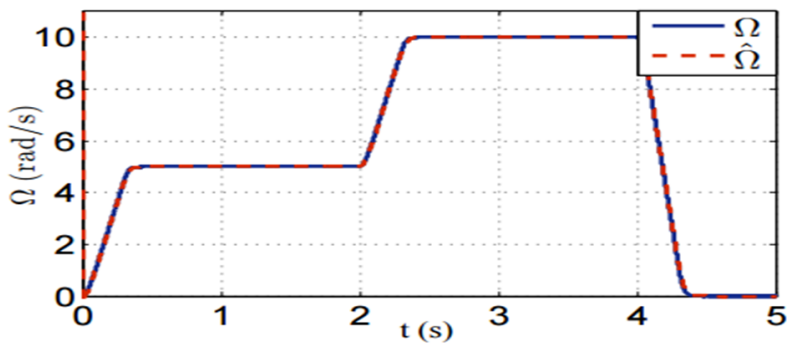

a. Actual and estimated speeds

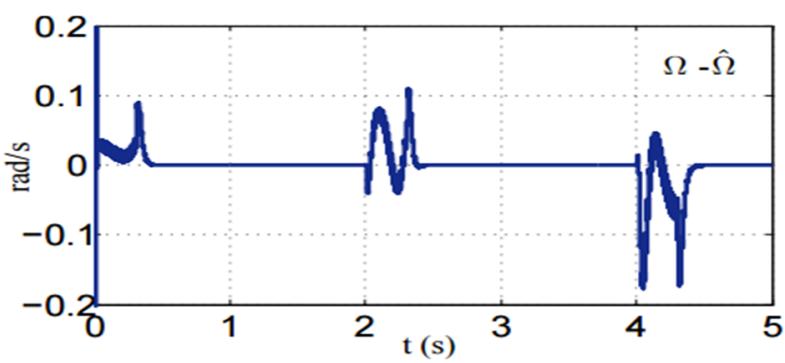

b. Rotor speed estimation error
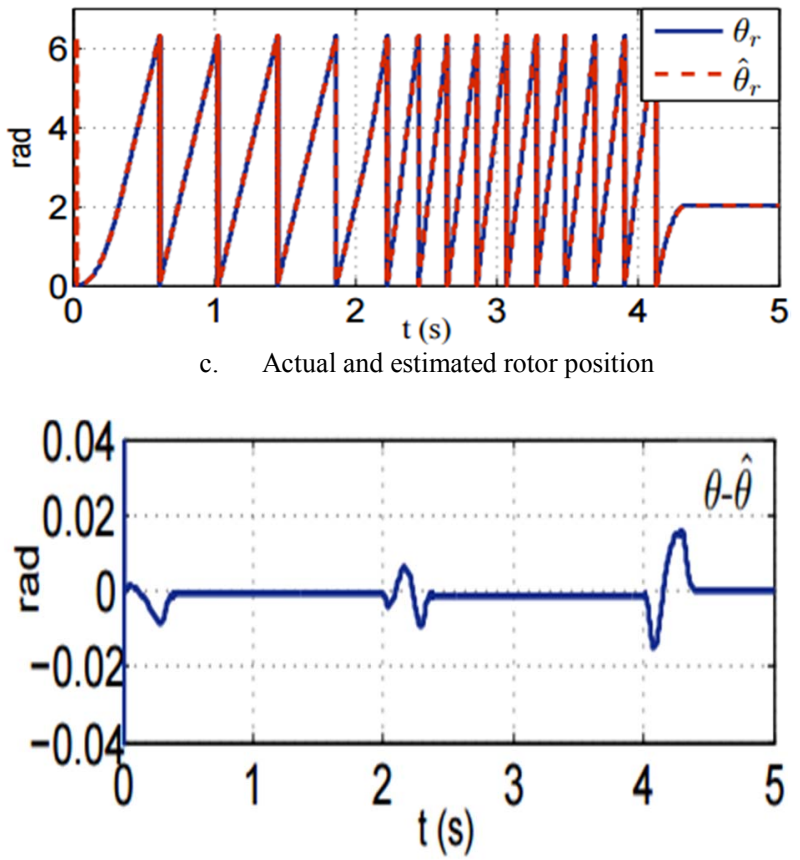

d. Rotor position estimation error

Fig.5. Speed and position waveforms under no load with the complete HFI method.

Fig.6 shows the waveforms of the PMSM drive with a time varying reverse speed reference and a step resistive torque of $1 \mathrm{Nm}$ applied in the time interval [1s, 4s]. These results show the performances of the mechanical rotor speed and rotor electric position tracking capabilities of the simplified HFI 
method. In steady state, the average speed and position estimation errors are almost zero.

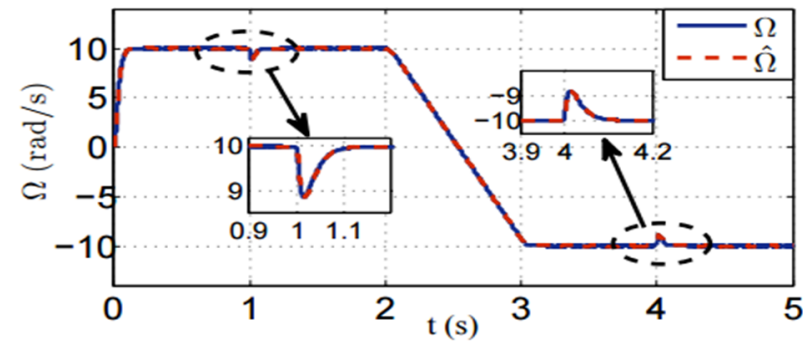

a. Actual and estimated speeds
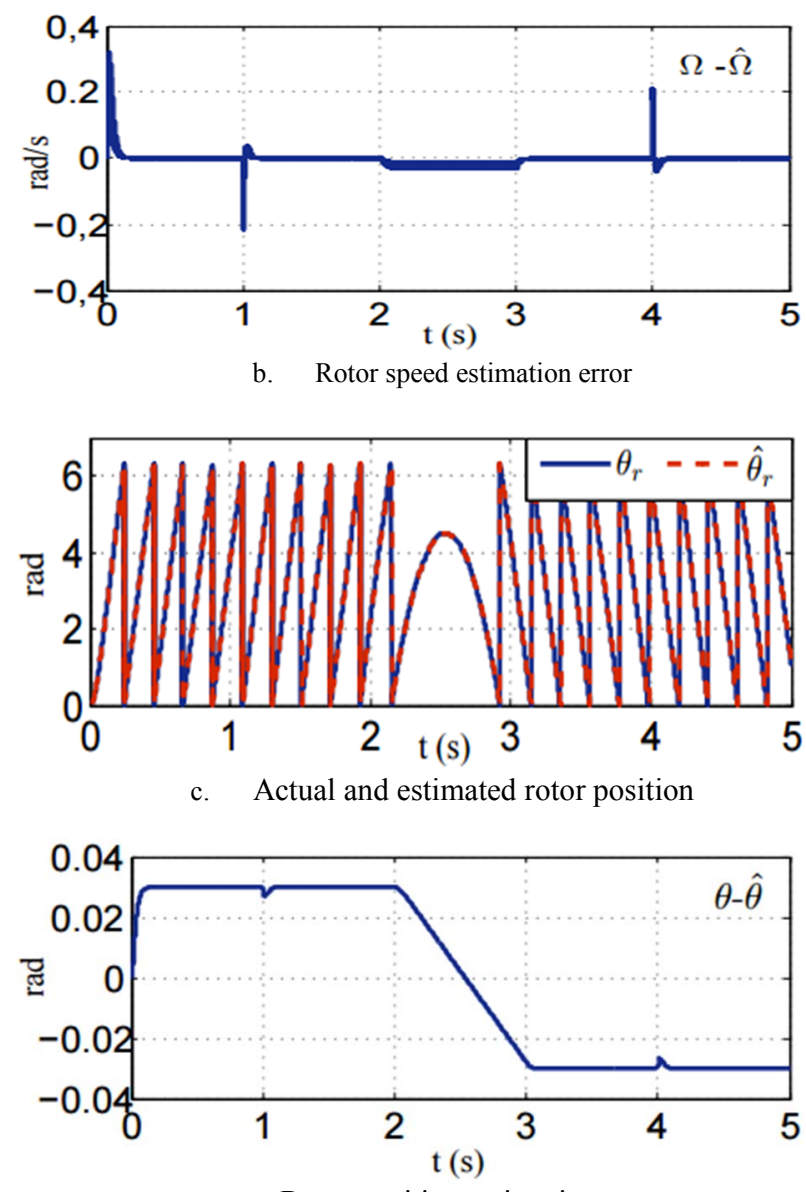

d. Rotor position estimation error

Fig.6. Speed and position under load torque during speed reversal test.

On figure 7, we have plotted the transformed currents. We can notice that the $\mathrm{d}$ component current is zero and the $\mathrm{q}$ torque current component follows the load torque variation.

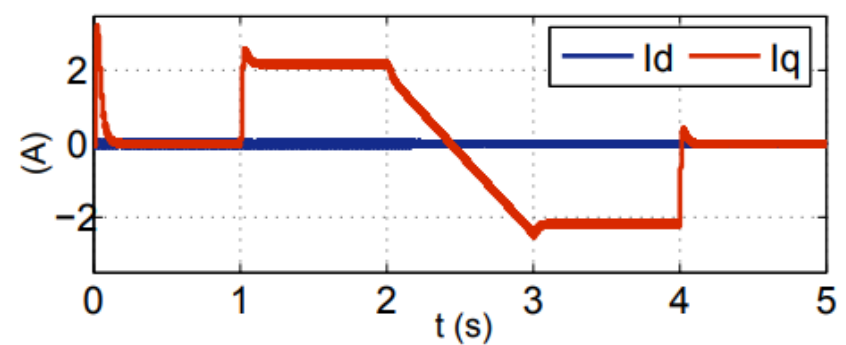

Fig.7. Park Transformed currents $\mathrm{i}_{\mathrm{d}}, \mathrm{i}_{\mathrm{q}}$

In the following, the robustness of the simplified HFI is evaluated against parameter variation with $\pm 50 \%$ variation introduced in the stator resistance Rs. The simulation results of the speed, position and the estimation errors displayed in figure 8 show that the estimation efficacy is not altered.
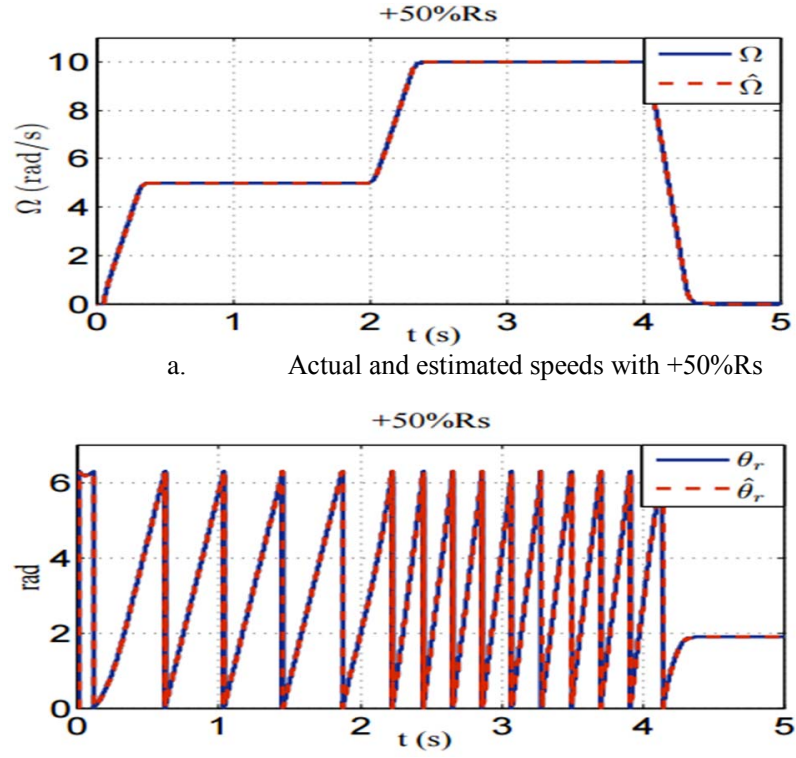

b.

Actual and estimated position with $+50 \%$ Rs
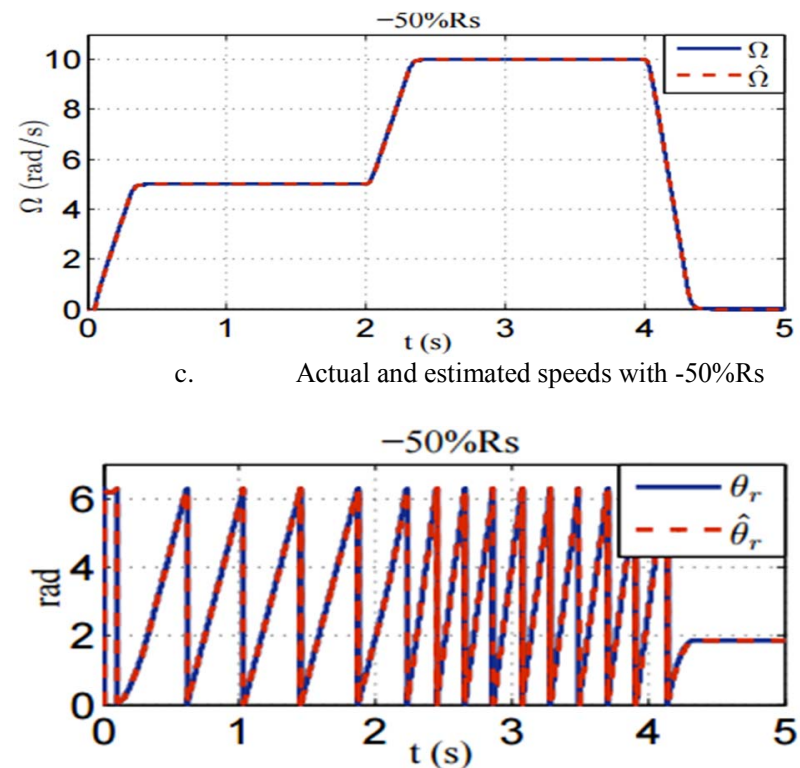

d. Actual and estimated position with $-50 \%$ Rs 

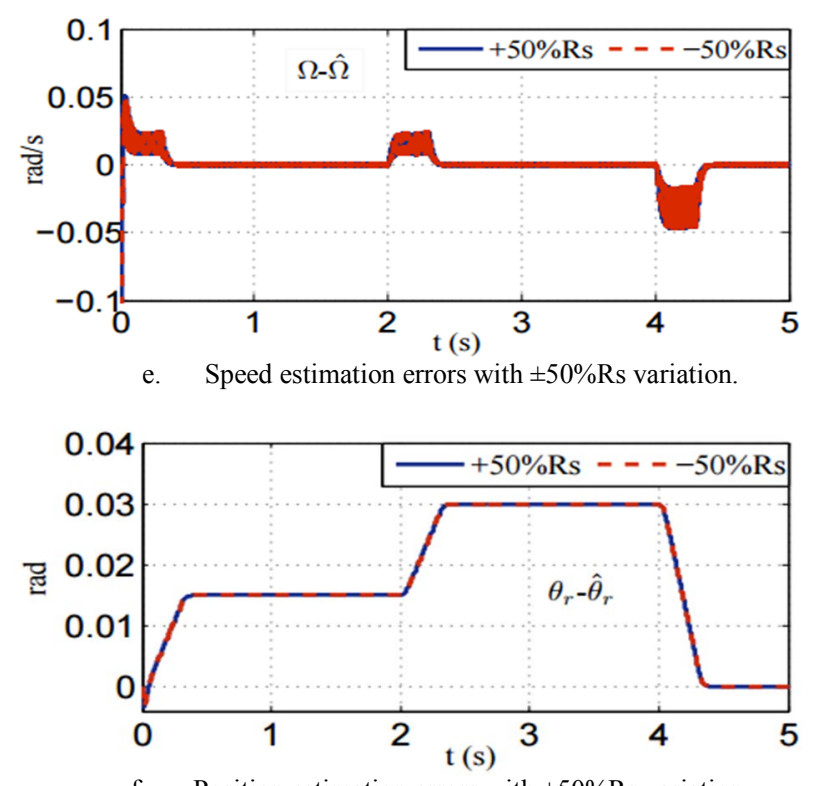

Fig.8. Speed and position robustness evaluation against stator resistance variations.

Fig. 8 shows the performances of the position and speed tracking capabilities of the Simple High Frequency Injection estimator in simulation at zero and low speeds.

\section{CONCLUSION}

PMSM drives without mechanical sensors are attractive because of lower cost and higher reliability. However the position information is mandatory for an efficient control. We have proposed in this paper to evaluate the position and speed estimation using a simplified structure of the High Frequency Injection. Its main advantage is its simplicity, as it requires only one filter. The simulation results show that the method is efficient at low speed and at standstill with and without load torque. The maximum mechanical position estimation error is lower than $0.035 \mathrm{rad}$ $\left(2^{\circ}\right)$ with a mean value lower than $0.017 \mathrm{rad}\left(1^{\circ}\right)$ in steady state. The method is therefore very promising for a sensorless drive.

\section{REFERENCES}

[1] O. Aydogmus, S. Siinter, " Implementation of EKF based sensorless drive system using vector controlled PMSM fed by a matrix converter, ," Inter- national Journal of Electrical Power and Energy Systems, 20 12, vol( 43),736 - 743 .

[2] J. Brahmi, L. Krichen, A. Ouali,"A comparative study between three sensorless control strategies for PMSG in wind energy conversion system," Journal of Applied Energy, 2009, vol. S6, 1565 - 1573.

[3] Z. Song, Z. Hou, C. Jiang, X. Wei, " Sensorless control of surface permanent magnet synchronous motor using a new method," Journal of Energy Conversion and Management, 2006, vol.47, 2451 - 2460.

[4] F. M. De Belie, P. Sergeant, J. A. Melkebeek, " A sensorless PMSM drive using modified high-frequency test pulse sequences for the purpose of a discrete-time current controller with fixed sampling frequency, " Journal of Mathematics and Computers in Simulation, 2010 , vol (S I), 367 - 3S1.
[5] S. Medjmadj, D. Diallo, M. Mostefai, C. Delpha and A. Arias, "PMSM Drive Position Estimation: Contribution to the HighFrequency Injection Voltage Selection Issue" IEEE Transactions on Energy Conversion, Vol. 30, No.1, pp. 349-358, Mar. 2015.

[6] M.J. Corley, R.D. Lorenz, "Rotor Position and Velocity Estimation for a Permanent Magnet Synchronous Machine at Standstill and High Speeds", Proc. IEEE-IAS 1996 Annual Meeting San Diego, CA, Oct. 5-10, pp.36-41, 1996.

[7] M.W. Degner, R.D. Lorenz, "Using Multiple Saliencies of the Estimation of Flux, Position, and Velocity in AC Machines", IEEE Trans. Ind. Appl., Vol. 34, No. 5, Sept./Oct., pp. 1097-1104, 1998.

[8] J. Cilia, G. M. Asher, K. J. Bradley, and M. Sumner, "Sensorless position detection for vector-controlled induction motor drives using an asymmetric outer-section cage, " IEEE Trans. Ind. Appl., vol. 33, no. 5, pp. 1162-1169, Sep./Oct. 1997.

[9] N. Teske, G. M. Asher, M. Sumner, and K. J. Bradley, " Encoderless position estimation for symmetric cage induction machines under loaded conditions," IEEE Trans. Ind. Appl., vol. 37, no. 6, pp. 1793 1800, Nov./Dec. 2001.

[10] O. Mansouri-Toudert, H. Zeroug, F. Auger, and A. Chibah, "Improved rotor position estimation of salient-pole PMSM using high frequency carrier signal injection," in Proc. IEEE Int. Conf. Mechatronics, Vicenza, Italy, Feb. 27-Mar. 1, 2013, pp. 761-767.

[11] S. Damkhi, M. S. Nait Said, and N. Nait Said, "Slotting effects and high frequency signal injection for induction machine rotor speed estimation," in Proc. Int. Conf. Expo. Elect. Power Eng., Iasi, Romania, Oct. 25-27, 2012, pp. 401-408.

[12] C. Silva, G. M. Asher, and M. Sumner, "Hybrid rotor position observer for wide speed-range sensorless PM motor drives including zero speed," IEEE Trans. Ind. Electron., vol. 53, no. 2, pp. 373-378, Apr. 2006

[13] A. Arias, C. Silva, G. M. Asher, J. C. Clare, and P. W. Wheeler, "Use of a matrix converter to enhance the sensorless control of a surfacemount permanent-magnet $\mathrm{AC}$ motor at zero and low frequency", IEEE Trans. Electron., vol. 53, no. 2, pp. 440-449, Apr. 2006. 